\title{
EVALUATION OF AN INTEGRATIVE APPROACH BETWEEN HBIM AND ARCHITECTURE HISTORY
}

\author{
S. Beltramo ${ }^{1}$, F. Diara $^{2 *}$, F. Rinaudo ${ }^{2}$ \\ ${ }^{1}$ DIST, Interuniversity Department of regional and urban studies and planning, Politecnico di Torino, Viale Mattioli 39, 10129 \\ Torino, Italy - silvia.beltramo@polito.it \\ ${ }^{2}$ DAD, Department of Architecture and Design, Politecnico di Torino, Viale Mattioli 39, 10129 Torino, Italy, \\ filippo.diara@polito.it, fulvio.rinaudo@polito.it
}

KEY WORDS: Architecture History, Cultural Heritage, Documentation, HBIM, Stratigraphic Analysis

\begin{abstract}
:
Restorative and conservative operations of Cultural Heritage buildings involve the historical and objective knowledge of the context. Meaning the knowledge as a diachronic awareness of the history of buildings should help the safeguarding processes of heritage assets.

The integration of historical information inside a HBIM platform involves huge benefits for the Cultural Heritage case management, its periodical monitoring operations and valorisation processes, moreover the historical evolution is correctly considered. This solution allows to maximize the comprehension and also communication of the analysed context through few simple steps as visualize, read and query in order to ensure the accuracy and quality of final data (Diara et al, 2018).

This new court of methodologic cooperation will be tested on the case study of the medieval Abbey of Staffarda (CN, Italy) and its refectory in a deeper way where, thanks to recent studies, it has been possible to reconstruct analysis map for a complete vision of the church and the Abbey's complex as well (Beltramo et al, 2019).
\end{abstract}

\section{INTRODUCTION TO STRATIGRAPHY}

Historical buildings are not generally considered as the result of a single constructive phase in either chronological terms and architectural stratification ones, quite the opposite indeed: expansion or demolition works, reconstructions of smaller cases and also the changing of the original designated use of the building. In this viewpoint stratigraphic analysis, originally used and implemented in the archaeological field, is a fundamental tool allowing the experts not only to create a surface map for the identification of the different chronological sequences of construction but also the progressing processes of materials transformation and degradation, due to natural and / or anthropological actions, as well voluntary and / or involuntary actions (Boato, 2008).Using this procedure, the architectural components could be analysed for example as architecture element and stratigraphic unit that, referred to historical buildings, could be related to masonry (USM) or render/plaster (USR); furthermore, masonry stratigraphic units should be classified as positive, negative or hidden, depending on constructive or destructive actions (Beltramo, 2009; Brogiolo et al, 2012). This kind of reading map (or critic survey) is an important step for the comparison operation between the structure of an historical building with its mechanical behaviours taking into account the specific events that have changed the building static asset (Doglioni, 1988).

Of course, the act of transferring an archaeological method to architectural fields brings with itself several comparative dynamics (comparative chronology) to detect chronological "phases" which must be supported and refined by further accurate analyses in order to reach a specified chronology (absolute chronology).

\section{INTEGRATION OF STRATIGRAPHY ON HBIM}

Stratigraphic units of an historical architecture would be innovative elements to be managed inside a BIM platform, where each one could be digitally linked to its history phases and enriched by new technical information of the structural elements.

The application of stratigraphic analysis, and then the detection of all interventions carried out on a historical building in a specific period, on HBIM project makes a significant contribution for the evaluation of risk and vulnerability elements, because constructive and destructive actions would be connected as architectural components to parametric model. Indeed, is relevant to think about USM and USR as building entities because in architectural terms these kinds of information regard masonry, wall cavity, render/plaster, decoration and other features.

Anyway, including and managing different data related to surfaces not directly connected with a common BIM and then without a specific architectural or structural classification is a difficult task and still an ongoing research field (Chiabrando et al, 2017). In other words, the nowadays challenge is to create a customized BIM workbench toll based on the stratigraphic evidences could be included, permitting the drawing and management of these units as parametric surfaces linked to the IFC (Industry Foundation Classes) model (Diara et al, 2018). Indeed, this kind of data may be represented approximated and classified graphically by customizing the materials database and by modifying the source code of architectural or environmental components of a parametric open source software, such as FreeCAD.

\section{A NOT CONVETIONAL HBIM}

Regarding Cultural Heritage investigations, the use of open source and free solutions could be considered a challenge today, 
because this adoption could be a good compromise to guarantee a complete data usability both for software and file formats. Moreover, the utilization of these solutions often allows adapting software to specific needs, overcoming commercial platforms and avoiding methodological stretches. In this sense, the adoption of FreeCAD software follow this thought because it allows us to operate inside its source code allowing modification and improvement (Diara et al, 2018). FreeCAD is a parametric modeller designed with different workbenches programmed and developed using Python open source environment; it allows the customization of specific commands and tools also modifying the source code. This possibility could include the modification of the definitions of building entities and architectural roles and definitions depending on the project needs and depending on IFC schema limitations and standard regulation.

Moreover, the creation of a relational database (created extracting data form IFC models), over the well-known benefits regarding the common recovery of the backup data (Logothetis et al, 2017) is fundamental to collect and query geometric and alphanumeric data (like stratigraphic unit analysis) that can be used to design and manage future interventions, to document the actual condition, to recreate previous situations of the object (Lo Turco et al, 2017). The complete analysis of a Cultural Heritage context could be carried out by interacting the extracted data form an IFC model (entities, elements, geometry, materials, etc.) and other kind of data linked to parametric objects, such as the historical evolution (Diara et al, 2018). In this regard, IFC objects are very important because they assume a kind of semantic dimension, because these objects are characterized by thematic descriptions such as architectural entities, roles, material, historical information (Messaoudi et al, 2018)

\section{EVALUATION OF AN EXPERIMENTAL WORKFLOW}

Against the background, this research starts from the intention to create an operative workflow for the integration on stratigraphic analysis on HBIM platform. For these reason Staffarda Abbey was investigate.

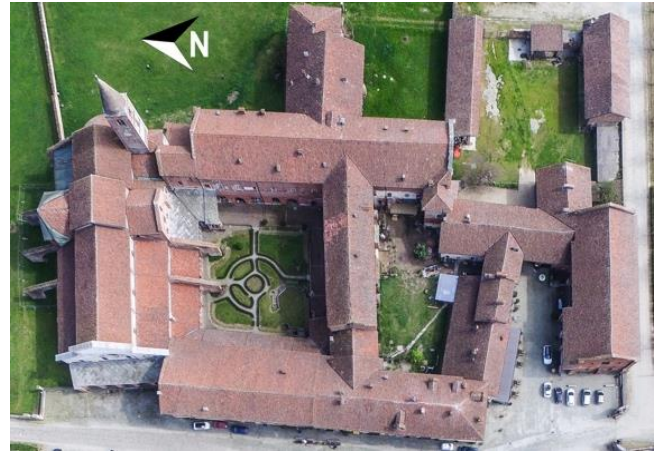

Figure 1. Staffarda Abbey view form APR (M. Roggero)

\subsection{Brief introduction to case study: Staffarda Abbey}

Staffarda (CN, Italy) is one of the most important Cistercian Abbey in Italy founded around 1135. All the monastery buildings are located around the cloister, also the church to the north side. These structures have experienced different constructions and structural changes in years, especially since the end of XVII century, because many areas of the abbey were destroyed and burnt by French armies (Beltramo, 2009).
For these events that have changed the morphology of the Cistercian complex and consequently different restoration construction sites, Staffarda Abbey has been the focus of recent studies and researches carried out in order to investigate the history and evolution of all different construction phases; indeed, analyses performed through Geographical Information Systems (GIS) tools have enabled to achieve good result for the purpose of having a complete historical vision of the church and the Abbey's complex (Beltramo et al, 2019).

This work will focus on the Refectory of Staffarda Abbey, located to the south side of the cloister and marked by morphological changes such as the vaulted ceiling. Moreover, up to now, the IFC model creation and investigation was carried out only for the east wall of the Refectory, characterized by different stratigraphic units, such as a filled entrance, the Ultima Cena fresco and a corner column.

\subsection{Data acquisition}

The decision to investigate the Staffarda Refectory took place in this research path, for its particular condition of being a really complex abbey in morphologically terms caused by several expansions and modifications works according to the intended use that during years modified the original morphology of several elements, especially the vaulted ceiling. Although these structural modifications, the refectory maintained the entire wall stratigraphy (Beltramo S., 2018). For these reasons were planned different surveys (LiDAR) in order to acquire metric and stratigraphic data for the complete analysis of the historical evolution of the refectory, trying to understand how this construction and evolution is placing inside the Staffarda complex.

In order to digitalize stratigraphic analysis were generated, staring form LiDAR point cloud, orthophotos for each internal wall. These raster images were used to read, draw up and numerate stratigraphy on CAD software (Figure 1).

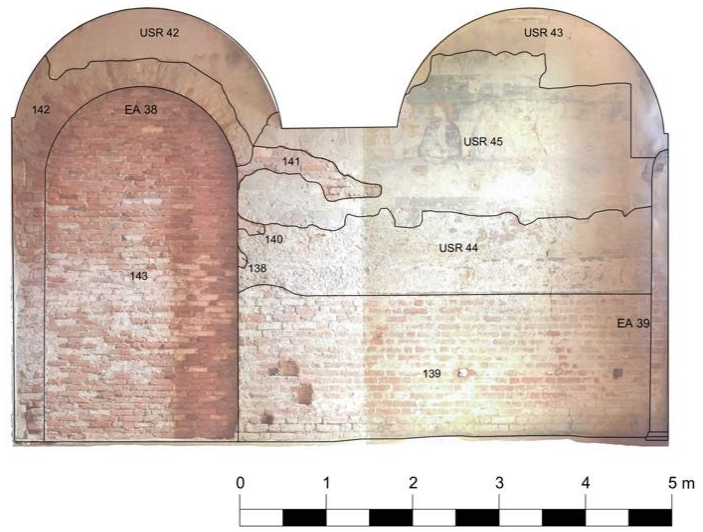

Figure 2. East Wall of the Refectory and its stratigraphic analysis

\subsection{FreeCAD preparation}

Inside FreeCAD the Arch workbench was thought to define all architectural entities of a building, such as wall, structure, window, roof, floor, component. The roles of these entities, thought for architectural design, can be extended and integrated following the historic architecture needs: for example, wall tool can be extended with roles as buttress, retaining wall, curtain wall; structure tool could include roles as wall cavity, door, window, load-bearing structure, arch; component tool could include roles as quoin, brick, roof tile. 
FreeCAD has a materials database that is referred to the MasterFormat classification used widely inside the most common BIM platforms. The default materials database is classified for architectural design and are not suitable for historical architecture. However, the materials editor tool allows the creation of a custom-made material library. For example, the new database could include specific information and properties of materials in a surveyed context. In this way, an HBIM project carried out with FreeCAD could integrates a customized materials database, depending on our needs.

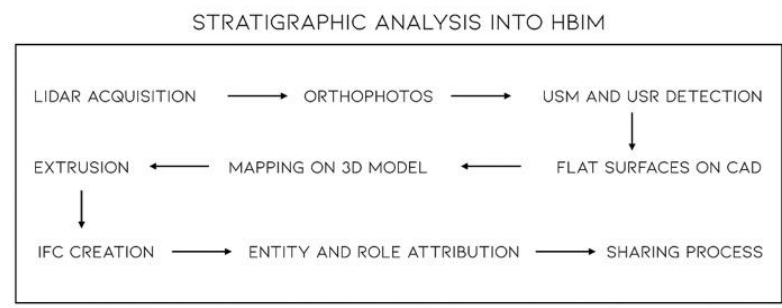

Figure 3. From stratigraphic analysis to IFC models

As far as the Refectory materials are concerned, the material editor was extended according to MasterFormat classification. In this sense were considered main sections such as: Masonry Metals - Wood, Plastic and Composites - Doors and Frames Finishes - Art. All these sections have progressive numbers for the identification. In particular, for the Refectory were selected these materials and numeric classification: Brick masonry 0421 13, Wall Finishes 0970 00, Decorative Finishes 0994 00, Stone Masonry 0443 00, Stone Fabrications 0443 16, Wood Beam 0606 10.16, Wood Doors 0814 00, Structural Rod 0517 00, Commissioned Paintings 121213.

The customization of roles involves the modification of source code of Arch workbench modules. As regard the Refectory, Building, Wall, Structure, Component are the main modules useful for creating IFC objects and also for attributing to these object particular architectural roles, and for these reasons have been included these entries, modifying each module (.py file):

- Building: Abbey, Refectory;

- Wall: Curtain Wall, Fresco, Cladding, Plaster, Retaining Wall, Wall cavity;

- Structure: Arch, Buttress, Capital, Column, Demi-Column, Door, Pillar, Single-lancet window, Window, Wood beam

- Component: Bolted end-plate, Brick, Quoin, Tie-Bar, Wall Layer

\subsection{Parametric modelling, IFC definition and DBMS}

Metric information derived from LiDAR acquisition were managed inside FreeCAD in order to create the 3D parametric model of the Refectory. According to different ways to create a parametric model (Chiabrando et al, 2017), the Refectory was modelling manually, then extracting geometries and volumes one by one. This method was the most suitable for historical buildings, due to the complexity of shapes and surfaces. For instance, parametric modelling of stratigraphic units, as Cultural Heritage assets, need to be though carefulness, mainly for the definition and classification of building elements and architectural components. These ones must be interpreted, represented and then approximated according to the level of detail (LOD) that the research needs (Lo Turco et al, 2017).

Indeed, parametric modelling of the Refectory was carried out thinking about the level of detail of stratigraphy, detail that strongly influences the complexity of the model. On final parametric model, according to right coordinate system and different XYZ working plans, orthophotos of the Refectory were imported and then stratigraphy was mapped out on the walls. Every parametric object become an HBIM semantic model by giving information and parameters in IFC file format. IFC is an open format used by the AEC industry (Architecture, Engineering and Construction) and it is referred to a parametric 3D object that briefly contain geometric information and associated data and rules (Barazzetti, 2016). In fact, an IFC model could considered as a dynamic database where it is possible to include a lot of information, such as the object's material, the physical relationships with other models, and the mechanical properties (Diara et al, 2018).

Up to now, the IFC creation has been tested only for the east wall of the Refectory, characterized by different stratigraphic units.

The east wall was modelling both creating a single vertical surface and drawing up each stratigraphic units of the wall: single surface in order to have a complete and homogenous model of the refectory compared to others walls and surfaces; on the other hand drawing all USM and USR for the purpose of having every single wall layers of the east wall and then of the others fronts of the refectory.

After parametric modelling, geometric elements and surfaces extracted from point clouds or orthophotos have been assigned to classes of objects (entities) and typological sub divisions (roles). In this sense an extruded surface from point clouds become an IFC parametric wall entity or an architectural structure with specific properties and materials that, combined with others, sets up a multilevel interactive building (Diara et al, 2018).

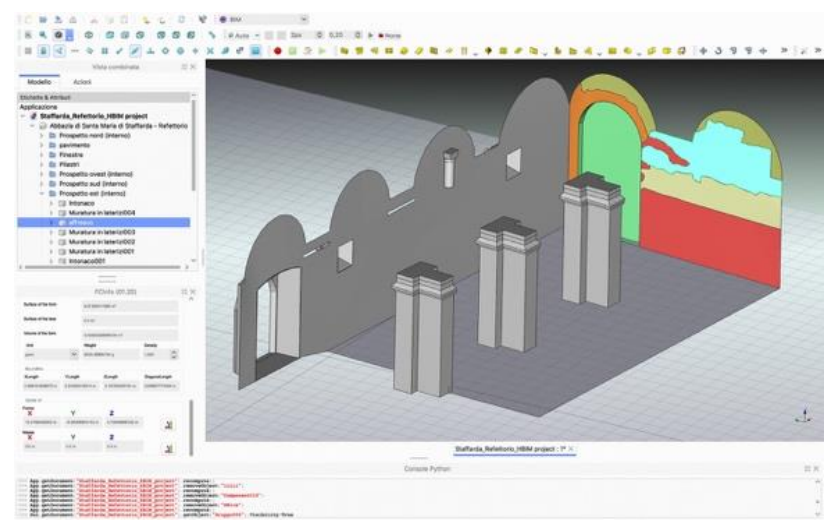

Figure 4. IFC model creation inside FreeCAD

Stratigraphic units of east wall of the refectory were classified as IFC wall entities. As regard the roles attribution all the 3D objects of the east wall can be classified as wall layer, anyway customized roles as fresco, plaster, curtain wall (for the filled entrance) could be used to identify the main function of a single unit. Moreover, materials are referred to brick masonry, wall finishes, commissioned paintings (fresco).

Despite wall layer classification could be include, for its general definition, all stratigraphic units. In this regard, customized roles could be thought just for specific stratigraphic units, such as USR (renders or plasters).

Information concerning IFC file, including building elements, materials, geometry, relationship and other properties, can be extracted and managed into DBMS (Diara et al, 2018). Extracted data form IFC models of Refectory has been stored and managed inside a relational a MySQL DBMS, that allows 
creating and managing relational database based essentially on tables that can be investigated through query processes.

For this purpose, the stratigraphic analysis of a Refectory related to IFC objects has been investigated through custommade relational query processes, allowing the investigation and comparison between stratigraphy and IFC properties, such as entities, roles and materials. In this sense, the historical evolution was observed and questioned thinking about specific and customizable needs of the research and of final distribution of the data and their relationships (Diara et al, 2018).

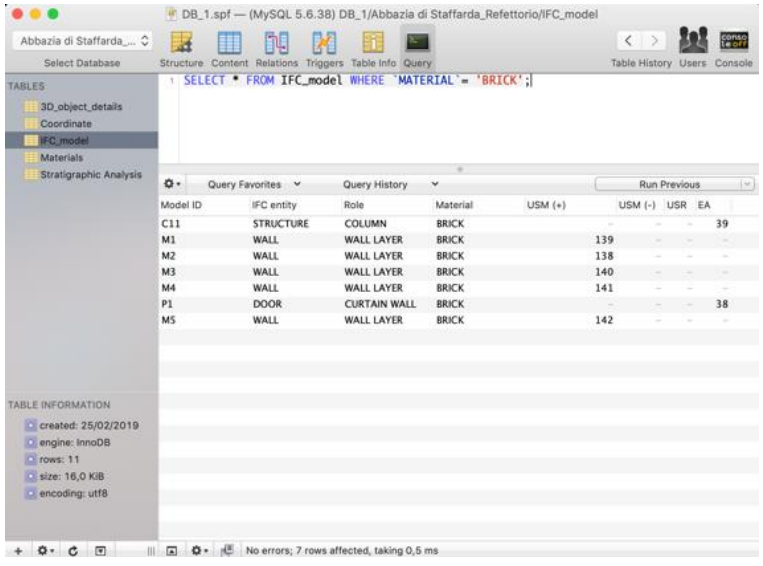

Figure 5. DBMS concerning IFC objects and stratigraphy

\subsection{Web Servers and viewers}

Sharing processes could be carry out using web servers and 3D viewers, solutions that allow overcoming the documentation and management issues. In this regard, web servers allow to work into a single platform where different professional figures can contribute to collect others information and data referred to a specific context. Moreover, 3D viewers are tools that allow, in addition to visualize the model, a simple querying of IFC objects based on entities identification, such as show or hide walls, columns, roof, windows, doors and others architectural entities.

This is the reason why, the final model of east wall of the Refectory was managed inside Solibri Model Viewer, that permits the visualization of the entire model tree and also IFC properties, such as identification, location, quantities, relations, classification, hyperlinks, can be visualized, checked and managed.

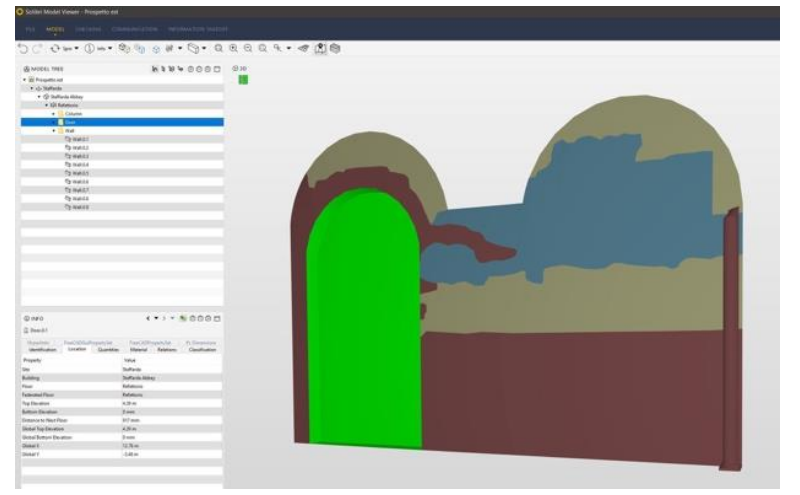

Figure 6. IFC model inside Solibri Model Viewer

\section{CONCLUSIONS}

This experimental workflow was useful in order to test and verify the integration of historic information inside a not common HBIM. This combination of methodologies and software provided and will be relevant for the historic reconstruction of the Refectory. In fact, acting with multidisciplinary is the right way to reconstruct, analyse and begin a critic knowledge process.

Including and managing surfaces and shapes related to stratigraphy is still an ongoing research field, especially for their classification, but by using open source solutions this limitation is not too pronounced, because software and IFC models can be edited depending our needs. Regarding IFC definitions, in this work we have run into MasterFormat classification, that was thought for architecture design and technical installations and for this reason its definitions and sub-divisions are not exactly fitting for Cultural Heritage assets. Indeed, they need specific definitions for the purpose to have a complete HBIM standard classification.

In addition to IFC creation, simplification is a necessary step to create an IFC parametric model of an historical building and it is due to the needs to combine the imperfection of the real geometry and the process of modelling shapes from point cloud. HBIM could be fundamental for restoration projects, due to its new possibilities for documentation of historical buildings: sharing different information inside a single (or almost) digital environment produce many advantages for a collaborative approach in order to have a clear and easy access schema of rapid intervention for the maintenance and consolidation of the Cultural Heritage context. Moreover, this experimental project based on HBIM creation for historic architecture could cooperate with other research carried out using GIS solutions (Beltramo et al, 2019) for the purpose to achieve a complete vision of all different construction phases, the historic evolution of the Abbey's complex, permitting further geospatial analyses. Moreover, the integration HBIM-GIS could be a sustainable solution in order to have a fitting data-set for conservative or restorative actions (Vacca et al, 2018).

Testing new methodologies and not common workflows is a reliable way to develop further approaches for the documentation, communication and then valorisation of researches carried out on a particular context. Consequently, technology should set up concrete relations and improve the immersion into a complete three-dimensional information.

\section{ACKNOWLEDGMENTS}

This work was supported and funded by the GAMHer project (Geomatics data Acquisition and Management for landscape and built Heritage in a European perspective), a 3 years project financed under the Italian PRIN 2015 framework (Progetti di Ricerca di Rilevante Interesse Nazionale).

\section{REFERENCES}

Barazzetti, L., 2016. Parametric as-built model generation of complex shapes from point clouds. In: Advanced Engineering Informatics, 30 (2016) 298-311

Beltramo, S., Donadio, E., Spanò, A., 2019. Stratigraphic Analyses, Historical Evidences, and 3D Documentation Tools. Deepening Built Heritage - New Researches for Historical 
Building Sites in Staffarda. In: Analysis, Conservation, and Restoration of Tangible and Intangible Cultural Heritage, pp.273-301, IGI Global

Beltramo, S., 2009. Stratigrafia dell'architettura e ricerca storica. Carocci editore, Roma, 2009.

Beltramo S., 2018. Nutrire il corpo e lo spirito: i refettori nei monasteri cistercensi. In Studi e Ricerche di Storia dell'Architettura. Rivista dell'Associazione Italiana Storici dell'Architettura (AISTARCH). Numero 3, anno 2, 2018. pp.38-51

Brogiolo, G.P., Cagnana, A., (a cura di), 2012. Archeologia dell'architettura. Metodi e interpretazioni. Firenze, All'Insegna del Giglio, 2012

Chiabrando, F., Lo Turco, M., Rinaudo, F., 2017. Modeling the decay in an HBIM starting from 3D point clouds. A followed approach for Cultural Heritage knowledge. In: The International Archives of the Photogrammetry, Remote Sensing and Spatial Information Sciences, Ottawa, Canada, Vol. XLII2/W5, pp.605-612

Diara, F., Rinaudo, F., 2018. Open source HBIM for Cultural Heritage: a project proposal. In: The International Archives of the Photogrammetry, Remote Sensing and Spatial Information Sciences, Riva del Garda, Italy, Vol. XLII-2, 2018 ISPRS TC II Mid-term Symposium "Towards Photogrammetry 2020", pp.303-309

Doglioni, F., 1988. La ricerca sulle strutture edilizie tra archeologia stratigrafica e restauro architettonico, in $\mathrm{R}$. Francovich - R. Parenti (a cura di), "Archeologia e Restauro dei monumenti”, (Pontignano 1987), Firenze, All'Insegna del Giglio, 1988

Lo Turco, M., Mattone, M., Rinaudo, F., 2017. Metric survey and BIM technologies to record decay conditions. In: The International Archives of the Photogrammetry, Remote Sensing and Spatial Information Sciences. Florence, Italy, Vol. XLII5/W1, 2017 Geomatics \& Restoration - Conservation of Cultural Heritage in the Digital Era, 22-24 May 2017, pp.261268

Logothetis, S., Valari, E., Karachaliou, E., Stylianidis, E., 2017. Spatial DMBS architecture for a free and open source BIM, In: The International Archives of the Photogrammetry, Remote Sensing and Spatial Information Sciences, Ottawa, Canada, Vol. XLII-2/W5, pp.467-473

Messaoudi, T., Véron, P., Halin, G., De Luca, L., 2018. An ontological model for the reality-based 3D annotation of heritage building conservation state. In: Journal of Cultural Heritage. Vol. 29, pp.100-112. 2018

Boato A., 2008. L'archeologia in Architettura. Misurazioni, stratigrafie, datazioni, restauro. Editore Marsilio, Collana Elementi, 2008

Vacca, G., Quaquero, E., Pili, D., Brandolini, M., 2018. GISHBIM integration for the management of historical buildings. In: The International Archives of the Photogrammetry, Remote Sensing and Spatial Information Sciences, Volume XLII-2, 2018 ISPRS TC II Mid-term Symposium "Towards
Photogrammetry 2020”, 4-7 June 2018, Riva del Garda, Italy. pp.1129-1135 